\title{
A Comparative Study of Lemongrass (Cymbopogon Citratus) Essential Oil Extracted by Microwave-Assisted Hydrodistillation (MAHD) and Conventional Hydrodistillation (HD) Method
}

\author{
Ranitha M., Abdurahman H. Nour, Ziad A. Sulaiman, Azhari H. Nour, and Thana Raj S.
}

\begin{abstract}
The demand of essential oil in current industry has increased due to its bioactive compound that shows various therapeutic effects. Microwave-assisted hydrodistillation (MAHD) is an advanced hydrodistillation (HD) technique, in which a microwave oven is used as the heating source. MAHD extraction of essential oil from Lemongrass (Cymbopogon Citratus) was studied. The effect of different parameters, such as water to plant material ratio $(6: 1,8: 1,10: 1)$, microwave power $(200 \mathrm{~W}, 250 \mathrm{~W})$ and extraction time $(30 \mathrm{~min}, 60 \mathrm{~min}$, $90 \mathrm{~min}, 120 \mathrm{~min})$ on the extraction yield and its major constituents were investigated and the results were compared with those of conventional HD. These essential oils were further analyzed by gas chromatography/mass spectrometric (GC-MS) to evaluate the effect of extraction method on the content of its main constituents which were neral, geranial and myrcene and some minor compounds such as linalool, geranic acid and citronellol. The optimum parameters were found at water to plant material ratio of $8: 1$, microwave power of $250 \mathrm{~W}$ and 90 minutes of extraction and the yield obtained under this condition was $1.46 \%$. GC-MS analysis has proved that the use of microwave irradiation did not adversely influence the composition of essential oils as the main constituents found through both methods were almost similar in term of quality and quantity. The results obtained indicate that MAHD method provided a good alternative for the extraction of essential oil from Lemongrass (Cymbopogon Citratus).
\end{abstract}

Index Terms-Extraction, GC-MS, lemongrass, microwave-assisted hydrodistillation, optimization.

\section{INTRODUCTION}

Essential oils are botanical extracts of various plant materials, and do not only originate from flowers, but from herbs, trees and various other plant material. It is estimated that the global number of plants is of the order of 300,000 and about $10 \%$ of these contains essential oils and could be used as a source for their production [1].Their extracts are formed

Manuscript received September 3, 2013; revised November 29, 2013. This work was supported in part by Universiti Malaysia Pahang under Grant GRS120356. Paper titles should be written in uppercase and lowercase letters, not all uppercase.

M. Ranitha, Abdurahman H. Nour, and Ziad A. Sulaiman Nour are with the Department of Chemical and Natural Resources Engineering, Universiti Malaysia Pahang, Kuantan, Malayisa (e-mail: ranitha_11@yahoo.com.my, nour2000_99@yahoo.com, ziad@ump.edu.my).

Azhari H. Nour is with the Department of Industrial Science and Technology, Universiti Malaysia Pahang, Kuantan, Malayisa (e-mail: azharihamid@ump.edu.my).

S. Thana Raj is with the Department of Electrical and Electronic Engineering, Universiti Teknologi Malaysia, Kuala Lumpur, Malaysia (e-mail: thana_raj1988@yahoo.com.my). by combination of diverse and complex volatile mixtures of chemical compounds, with predominance of terpene associated to aldehydes, alcohols, and ketones which were accumulated in various structure of the plant [2]. In industry, the essential oils are typically extracted from fresh or partially dried leaves using various method of extraction and the most common will be hydrodistillation. The use of medicinal plants extracts is part of a competitive market, which includes pharmaceuticals, food, cosmetics, and perfumery markets, mainly to use their active substance. The Asian continent with its diversity of climates appears to be the most vital producer of essential oils. China and India play a major role followed by Indonesia, Sri Lanka, and Vietnam [1].

Lemongrass (Cymbopogon Citratus), a perennial plant with long, thin leaves, is one of the largely cultivated medicinal plants for its essential oils in parts of tropical and subtropical areas of Asia, Africa and America [3]. It contains $1-2 \%$ of essential oil on dry basis [4] and the chemical composition of Lemongrass (Cymbopogon Citratus) essential oil is varying widely upon genetic diversity, habitat and agronomic treatment of the culture [5].The leaves of Lemongrass (Cymbopogon Citratus) present lemony characteristic flavor due to its main content, citral which present great importance to the industry. Citral, a combination of neral and geranial isomers, is used as a raw material for the production of ionone, vitamin $\mathrm{A}$ and beta-carotene [4]. There were a number of studies carried out to prove the anti-oxidant, anti-microbial and anti-fungal activities of Lemongrass (Cymbopogon Citratus) [6]-[8].

The common methods to extract essential oil from medicinal plant, including for Lemongrass (Cymbopogon Citratus), are hydrodistillation (HD), steam distillation, steam and water distillation, maceration, empyreumatic( or destructive) distillation and expression [9]. It is proved through a number of studies, [9]-[11], that the quality of essential oil mainly depends on its constituents which is primarily influenced by their extraction procedures. In contrast, these common methods can induce thermal degradation, hydrolysis and water solubililization of some fragrance constituents. . In addition, the oil obtained through solvent aided extraction contains residues that pollute the foods fragrances to which they are added. As a means to overcome this sort of drawbacks, an advance and improved method such as microwave-assisted extraction [12], ohmic-assisted hydrodistillation [13], subcritical water extraction [14] and ultrasound-assisted extraction [15] have 
been applied to shorten extraction time, improve the extraction yield and reduce the operational costs.

Recently, microwave-assisted hydrodistillaton (MAHD) procedures for isolating essential oils have become attractive for use in laboratories and industry due to its effective heating, fast energy transfer and also an environmental friendly extraction technique. Its acceptance as potential and powerful alternative for conventional extraction techniques has been proved through several research [9], [10], [14]. However, there are no reports of the simultaneous comparison of MAHD and HD extraction procedures on extraction of essential oil from Lemongrass (Cymbopogon Citratus). Therefore, the aim of the present study was to investigate the applicability of microwave-assisted hydrodistillation (MAHD) technique as an alternative to conventional hydrodistillation (HD) in isolation of Lemongrass (Cymbopogon Citratus) extracts based on the extraction yield and constituents of oils obtained under optimized condition. The effect of operational parameter such as extraction time and water to raw material ratio were evaluated to identify its optimum condition for extraction and this applicability was appreciated by using the result of subsequent GC/MS analysis by comparing their main constituents and oxygenated compounds.

\section{MAterials AND MethoD}

\section{A. Plant Samples}

Lemongrass (Cymbopogon Citratus) leaves were collected from home garden in northwest of Malaysia. The plant sample was freshly cut, $10 \mathrm{~cm}$ from the root, in the morning of the day they were collected. According to [16], for Lemongrass (Cymbopogon Citratus), the percentage essential oil yield for the partially dried leaves was found to be higher than that of the fresh leaves. Thus, once collected, the plant material were dried at room temperature for a week then kept in a sealed plastic bag at ambient temperature and protected from the light. The samples were ground using a kitchen grinder (Super Blender,Panasonic,Tokyo, Japan) at room temperature prior to extraction. Whereas, extraction yield increase by decreasing the particle size due to the higher amount of oil released as the leave cells are destroyed by milling [17]. In order to improve the collection efficiency, the plant material was soaked in its distilled water for $30 \mathrm{~min}$ before the extraction performed.

\section{B. Reagents}

Anhydrous sodium sulfate and n-hexane used was analytical grade reagent purchased from Sigma Aldrich (US) and Fisher Scientific (US), respectively. Deionised water used was purified by Milli-Q purification system (Millipore) (Massachusetts,USA).

\section{Microwave-Assisted Hydrodistillation}

A modified domestic microwave oven model Samsung MW71E connected to the Clevenger apparatus was modified for MAHD operation. The Samsung MW71E has 1150 Watt power consumption, 800 Watt output power with $250 \mathrm{v}-50 \mathrm{~Hz}$ power soure; $2450 \mathrm{MHz}$. The cavity dimensions of the microwave oven were $306 \times 211 \times 320 \mathrm{~mm}$. The microwave-assisted hydrodistillation were conducted at water to raw material ratio of $6: 1,8: 1$ and $10: 1$ at 200 and 250W microwave power for durations of 30, 60, 90 and 120 min. $2 \mathrm{~h}$ of extraction is sufficient enough to extract essential oil from the sample through MAHD [14]. The flask containing $50 \mathrm{~g}$ of Lemongrass (Cymbopogon Citratus) with its distilled water was placed within the microwave oven cavity. A condenser which has been set on the top, outside the oven, was used to collect the extracted essential oils.

\section{Hydrodistillation}

$50 \mathrm{~g}$ of fresh Lemongrass (Cymbopogon Citratus) leaves were placed in a $1 \mathrm{~L}$ flask containing $400 \mathrm{ml}$ of distilled water and hydrodistilled for 30, 60, 90, and $120 \mathrm{~min}$ using a Clevenger-type apparatus. The system was operated at a fixed power of 500W and under atmospheric pressure [18].

\section{E. Analysis of Sample}

To remove water, the collected extracts were dried over anhydrous sodium sulfate, weighed and stored in vial at +4 ${ }^{\circ} \mathrm{C}$ prior to analysis. The amount of yield obtained from the extraction was analyzed to evaluate the performance of MAHD in Lemongrass (Cymbopogon Citratus) oil extraction. Yield of oil that obtained for every run was calculated by using Equation (1):

$$
\text { Yield of essential oil }=\frac{\text { amount of essential oil }(\mathrm{g}) \text { obtained }}{\text { amount of raw materials }(\mathrm{g}) \text { used }}
$$

A GC-MS instrument (5973N, Agilent Technologies, Wilmington, DE, UAS) equipped with a mass selective detector operating in the electron impact mode $(70 \mathrm{eV})$ was used to study the composition of the essential oil at extracted various group of parameter condition to analyze its quality. The GC part (6890N, Agilent Technologies, Palo Alto, CA, USA) was equipped with an HP-5MS (Agilent BTechnologies) capillary column (30 m long, $0.25 \mathrm{~mm}$ id and $0.25 \mathrm{~lm}$ film thickness). Temperature-programming of the oven included an initial hold at $50{ }^{\circ} \mathrm{C}$ for $5 \mathrm{~min}$ and a rise to $240{ }^{\circ} \mathrm{C}$ at $3{ }^{\circ} \mathrm{C}$ min- 1 followed by additional rise to $300{ }^{\circ} \mathrm{C}$ at $5{ }^{\circ} \mathrm{C} \mathrm{min}-1$. A final hold for $3 \mathrm{~min}$ was allowed for a complete column clean-up. The injector was set at $280{ }^{\circ} \mathrm{C}$. The samples were diluted with n-hexane $(1 / 10, v / v)$ and a volume of $1.0 \mu \mathrm{l}$ was injected to the GC with the injector in the split mode (split ratio: 1/10). Carrier gas, He, was adjusted to a linear velocity of $1 \mathrm{ml} \mathrm{min-1[19].} \mathrm{The}$ compounds of the extracted essential oils were identified by comparing their mass spectral fragmentation patterns with those of similar compounds from a database (Wiley/NBS library) or with published mass spectra (Massada 1976; Adams, 2001). The components were quantified based on the comparison of compound's retention period, which were similar in both techniques. The normalization method was used; the value of total peak areas is considered $100 \%$ and the percentage of each component was calculated using the area of each peak.

\section{RESULTS AND DISCUSSION}

\section{A. Optimization of MAHD Method}

Quality and quantity of oil essential mainly depends on the 
extraction procedures. Therefore, optimizing extraction procedure is considered as a vital process. In current research, the following parameters were studied to identify the optimum operating condition of MAHD in extraction of essential oil from Lemongrass (Cymbopogon Citratus) : water to raw material ratio,6:1, 8:1 and 10:1; microwave power, $200 \mathrm{~W}$ and $250 \mathrm{~W}$; extraction time, $30 \mathrm{~min}, 60 \mathrm{~min}$, $90 \mathrm{~min}$, and $120 \mathrm{~min}$.

Effect of water to plant material ratio-Fig. 1(a) shows that the extracted yield at three different water to plant material ratio at $90 \mathrm{~min}$ of extraction and under $250 \mathrm{~W}$ microwave power. By decreasing the water to plant material ratio from $10: 1$ to $8: 1$, the extracted oil yield increased from $0.89 \%$ to $1.46 \%$. However, the extracted oil yield decreased to $1.27 \%$ when the ratio is reduced to $6: 1$. Thus, ratio $8: 1$ is the selected as the optimum ratio for the extraction as it's gave the maximum yield. The effect of water to plant material ratio needs crucial consideration to achieve maximum extraction of yield during scaling up or down the sample preparation method. The small volume of water in the system failed to withstand at high microwave intensity for a longer extraction time and target extraction incomplete. While, presence of excess amount of water can cause excess thermal stress due to rapid heating of the solution on account of effective absorption of microwaves by water [9].

Effect of Microwave Power-Microwave power is one of the factors that influence the efficiency of MAHD extraction because the microwave energy significantly affects molecular interactions between the target compounds and others. Two microwave power levels were used in the extraction and their results were shown in Fig. 1(b) (at water to raw material ratio $8: 1$ and 90 min of extraction time). The extraction was improved by raising the microwave power from $200 \mathrm{~W}$ to $250 \mathrm{~W}$ with $1.21 \%$ and $1.46 \%$, respectively. This is doubtlessly due to the rapid generation of heat inside the immersed Lemongrass (Cymbopogon Citratus) with the absorption of microwave energy and the subsequent formation of a higher pressure gradient inside the plant material when subjected to higher microwave power levels. Based on these results, $250 \mathrm{~W}$ was chosen as the optimum microwave power. The obtained result is in accordance with [10] finding on effect of microwave power on extraction of Echinophora platyloba DC using MAHD.

Effect of Extraction Time-Fig. 1(c) shows the influence of microwave power on the extraction yields of Lemongrass (Cymbopogon Citratus) over the range 30-120 min under a fix microwave power of $250 \mathrm{~W}$ and water to raw material ratio of $8: 1$. From the graph, the amount of yield does not change significantly after 90 minutes where the yield obtained up to this period was $1.46 \%$. The rate of extraction was high at the beginning of the extraction but get slow gradually by time. The effect of this parameter in MAHD has been studied by number researches on various plant materials, [10], [19], [20] and almost all of them obtained the same configuration as illustrated in Fig. 1(c). These results confirmed the Fick's second law of diffusion which stated about the final equilibrium achieved by the solute concentrations in plant matrix and in the solvent after a certain time. This cause into no significant improvement in oil yield when prolonging the extraction time.

\section{B. Comparison of Lemongrass (Cymbopogon Citratus)} Oil Obtained by Conventional Hydrodistillation Method

To evaluate the effect of microwave in the extraction of essential oil, the results of MAHD, at optimal conditions, were compared with those of conventional hydrodistillation (HD) in term of the oil yield and its constituents. HD is an accepted method that is used as reference for the quantification of essential oils [11].

The induction time for MAHD was only 12 minutes whereas for HD it was $30 \mathrm{~min}$. This show, $60 \%$ of the total oil can be extracted using MAHD by the time the extraction of essential oil by HD started. It is interesting to note that, the amount of yield extracted by MAHD after $60 \mathrm{~min}$ will similar as the oil resulted after $180 \mathrm{~min}$ by HD. At $90 \mathrm{~min}$ of extraction, the oil yield by MAHD and HD method were $1.46 \%$ and $0.98 \%$, respectively.

(a)

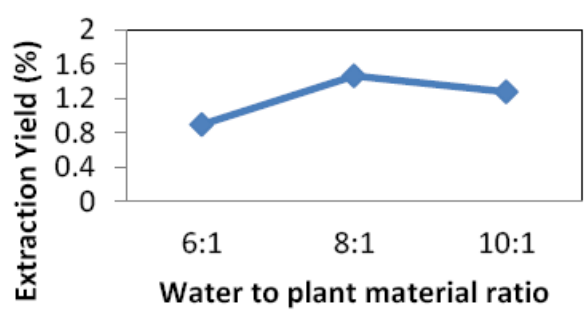

(b)
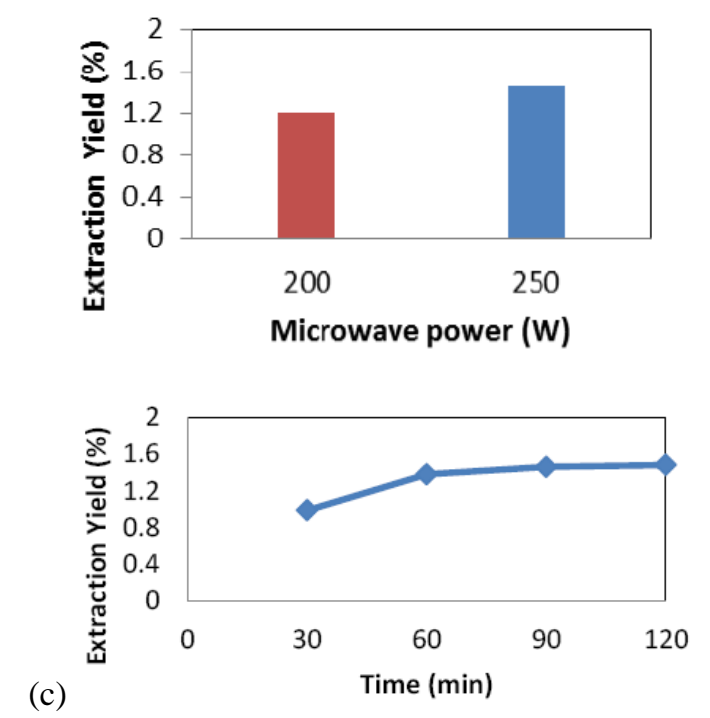

Fig. 1. Effect of (a) water to raw material ratio, (b) microwave power and (c) extraction time using MAHD on the extraction yield of essential oil from Lemongrass (Cymbopogon Citratus).

This momentous heating rate is due to the microwaves which deliver bulk heating within the system. These create an instant and high rate heating platform. All this results indicated a substantial saving in time, energy and as well as its cost.

GC-MS analyses were performed with the aim to compare the compositions of the Lemongrass (Cymbopogon Citratus) oil extracted by MAHD and HD. The comparison of major compounds found in their optimized condition, neral, geranial and myrcene, and some minor components are shown in Table I. Citral, the combination of the neral and geranial isomers, is the key compound to evaluate the quality of Lemongrass (Cymbopogon Citratus) oil. From the results, 
it was observed that concentration of key compound found in the Lemongrass (Cymbopogon Citratus) oil were almost similar for both methods. Moreover, the oil compositions revealed that higher amounts of oxygenated monoterpenes such as linalool, geranic acid and citronellol are present in the essential oil isolated by MAHD and absence in HD. This difference could be attributed to the microwave radiation effect that can penetrate into biological materials and creates heat by interaction with polar molecules, water. This heat cause damage into the cells spread and facilitates the release of active compound from its glands and ultimately improves the efficiency of the extraction process, [10]. Taking into account the comparison studies of extraction method between MAHD and HD by other researchers on different plants, it seems the constituents and their concentrations obtained by both of method were almost similar [18], [19], [21]. All these results have proved that microwave greatly accelerated the extraction process, but without causing significant affect in the volatile oil composition.

By considering the chemical profile of the essential oil of Lemongrass (Cymbopogon citratus) from northwest of Malaysia and reports of other scientist, it shows there are significant quantitative differences between the chemical profiles of the major components of the essential oil [22], [3], [2]. According to [10], these variations may due to the diverse climatic and geographic differences and at the same time to different harvesting times and extraction procedures.

TABLE I: COMPOSITION OF LEMONGRASS (CYMBOPOGON CITRATUS) OIL OBTAINED BY MAHD AND HD

\begin{tabular}{|l|c|c|}
\hline \multirow{2}{*}{ Compound } & \multicolumn{2}{|c|}{ Relative peak area (\%) } \\
\cline { 2 - 3 } & MAHD & HD \\
\hline Myrcene & 3.96 & 9.91 \\
\hline Neral $^{\mathrm{a}}$ & 35.69 & 35.67 \\
\hline Geranial $^{\mathrm{b}}$ & 50.81 & 49.46 \\
\hline Citral $^{\text {a+b }}$ & 86.48 & 85.15 \\
\hline Geranic acid & 3.33 & - \\
\hline Linalool & 0.48 & - \\
\hline Citronellol & 0.50 & - \\
\hline
\end{tabular}

\section{CONCLUSIONS}

In this paper, microwave-assisted hydrodistillation method was optimized based on the three tested parameters namely water to plant material ratio, microwave power and extraction time. Then, the results were compared with essential oil obtained by conventional hydrodistillation. MAHD offer great advantages over conventional HD. MAHD require shorter extraction time (90 min vs $180 \mathrm{~min}$, respectively). The extraction of the essential oil from Lemongrass (Cymbopogon Citratus) by MAHD under this optimized conditions provided additional benefits of microwave irradiation in isolation of essential oils. In addition, GC-MS results proved that there were no significant difference between the constituents of essential obtained by MAHD and those obtained by conventional HD. Due to the substantial saving of time, cost and energy with no significant changes in its constituents, MAHD process is a good alternative in the extraction processes of essential oil from Lemongrass (Cymbopogon Citratus). The result obtained from this study encourage applying the MAHD for the extraction of the essential oil of some other plant materials

\section{REFERENCES}

[1] K. C. B. Husnu and B. Gerhard, Handbook of Essential Oils: Science, Technology, and Applications, Taylor and Francis Group, NW, 2010.

[2] N. E. Tajidin, S. H. Ahmad, A. B. Azimah, and M. Munirah, "Chemical Composition and Citral Content in Lemongrass (Cymbopogon Citratus) essential oil at three maturity stages," International Journal of Biotechnology, vol. 11, no. 11, pp. 2685-2693, February 2012.

[3] S. Chanthal, S. Prachakoli, and C. Ruangviriyachai, "Influence of extraction methodologies on the analysis of five major volatile aromatic compounds of citronella grass and lemongrass grown in Thailand," Journal of AOAC International, vol. 95, pp. 763-772, 2012.

[4] L. H. C. Carlson, C. B. S. Machad, L. K. Pereira, and A. Bolzan, "Extraction of lemongrass essential oil with dense carbon dioxide," Journal of Supercritical Fluids, vol. 21, pp. 33-39, 2001.

[5] L. Paviani, S. B. C. Pergher, and C. Dariva, "Application of molecular sieves in the fractionation of lemongrass oil from high-pressure carbon dioxide extraction," Brazilian Journal of Chemical Engineering, vol. 23, pp. 219-22, 2006.

[6] G. K. Oloyede, I. A. Oladosu, and A. F. Shodia, "Chemical Composition and Cytotoxicity of the essential oils of Crinum ornatum (Ait) Bury," African Journal of Pure and Applied Chemistry, vol. 4, no. 3, pp. 35-37, 2010

[7] J. Behboud, E. Amirreza, M. A. Babak, and H. Zarifeh, "Antibacterial Activities of Lemon Grass Methanol Extract and Essence on Pathogenic Bacteria," Journal of Agricultural and Environmental Science, vol. 12, no. 8, pp. 1042-1046, 2012.

[8] G. T. Nikos and D. E. Costas, "Antifungal activity of lemongrass (Cympopogon Citratus L.) essential oil against key postharvest pathogens," Innovative Food Science Emerging Technology, vol. 8, pp. 253-255, 2007.

[9] M. Dhobi, V. Mandal, and S. Hemalatha, "Optimization of microwave assisted extraction of bioactive flavonolignan-silybinin," Journal of Chemical Metrology, vol. 3, no. 1, pp. 13-23, 2009.

[10] J. Ashgari, C. K. Touli, and M. Mazaheritehrani, "Microwave-assisted hydrodistillation of essential oils from Echinophora platyloba DC," Journal of Medicinal Plants Research, vol. 6, no. 28, pp. 4475-4480, 2010

[11] K. Sibel, N. Sedef, K. Nural, S. Sahin, S. Gulum, and B. Beste, "Microwave-assaited hydrodistillation of essential oil from rosemary," Journal of Food Science Technology, 2012.

[12] H. Wang, Y. Liu, S. Wei, and Z. Yan, "Comparative seasonal variation and chemical composition of essential oils from the leaves and stems of Schefflera heptaphylla using microwave-assisted and conventional hydrodistillation," Journal of Indutrial Crops and Product, vol. 36, pp. 229-237, 2010.

[13] G. Mohsen, F. Asgar, J. Katayoun, and M. Mahsa, "Comparison of ohmic-assisted hydrodistillation with traditional hydrodistillation for the extraction of essential oil from Thymus vulgaris L.," Journal of Innovative Food Science and Emerging Technology, vol. 14, pp. 85-91, 2012.

[14] H. E. Mohammad, G. Fereshteh, and R. Soosan, "Subcritical water extraction of eesential oil from coriander seeds (Coriandrum sativum L.," Journal of Food Enginnering, vol. 80, pp. 735-740, 2007.

[15] C. D. Porto and D. Decorti, "Ultrasound-assisted extraction coupled with under vacuum distillation of flavor compounds from spearmint (carvone-rich) plants: Comparison with conventional hydrodistillation," Ultrason Sonochem, vol. 16, pp. 795-799, 2009.

[16] M. S. Edwin, G. Leornard, and G. Elijah, "Isolation and Identification of essential oil from Cymbopogon Citratus (Stapf) using Gc-Ms and Ft-Ir," Chemistry and Material Research, vol. 2, no. 4, pp. 13-22, 2012.

[17] G. Wenqiang, L. Shufen, Y. Ruixiang, T. Shaokun, and Q. Can, "Comparison of essential oils of clove buds extracted with supercritical carbon dioxide and other three traditional extraction methods," Journal of Food Chemistry, vol. 10, pp. 1558-1564, 2007.

[18] Y. Liu, L. Yang, Y. Zu, J. Zhao, Y. Zhang, Z. Zhang, and W. Wang, "Development of an ILMS method for simultaneous extraction and distillation for determination of proanthocyanidins and essential oil in Cortex cinnamomi," Journal of Food Chemistry, vol. 135, pp. 2514-2521, 2012. 
[19] G. M. Taghi and R. Karamatollah, "Comparison of microwave-assisted hydrodistillation with the traditional htdrodistillation method in the extraction of essential oil from Thymus vulgaris L.," Journal of Food Chemistry, vol. 109, pp. 925-930, 2008.

[20] H. M. Hazwan, C. M. Hasfalina, J. Hishamuddin, and Z. A. Zurina, "Optimization and kinetics of essential oil from Citronella grass by ohmic heated hydrodistillation," International Journal of Chemical Engineering and Applications, vol. 3, pp. 173-177, 2012.

[21] A. B. L. Djouahri and Y. B. Meklati, "Effect of extraction method on chemical composition, antioxidant and anti-inflammatory activities of essential oil from the leaves of Algerian Tetraclinis articulate Masters," Journal of Industrial Crops and Products, vol. 44, pp. 32-36, 2013.

[22] A. R. M. Hanaa, Y. I. Sallam, A. S. E. Leithy, and S. E. Aly, "Lemongrass (Cymbopogon Citratus) essential oil as affected by drying methods," Annals of Agricultural Science, vol. 57, no. 2, pp. 113-116, 2012.

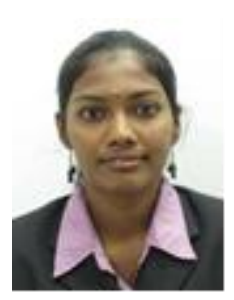

Ranitha Mathialagan was born in Perak, Malaysia on October 11, 1988. She was completed her Diploma in Chemical Engineering (bioprocess) in 2009 at Universiti Kuala Lumpur (MICET), Melaka, Malaysia then persued her Bachelor Degree of chemical engineeing at Universiti Malaysia Pahang, Pahang, Malaysia and completed on 2012. Currently, she persuing her studies at Universiti Malysia Pahang in Master of Engineering (chemical), in the topic of herbal extraction through microwave-assisted hydrodistillation. M. Ranitha has done her practical training for 3 months in Department of Environment, Perak, Malaysia. She has published a book titled Extraction and characeterization of essential oils by MAHD method; Germany: LAP LAMBERT, 2012 and a paper titled Extraction and Characterization of Essential Oil from from Ginger (Zingiber Officinale Roscoe) and Lemongrass (Cymbopogon citratus) by Microwave-Assisted Hydrodistillation, International Journal of Chemical and Environmental Engineering, vol. 4(4), pp.221-226, 2013. 